\title{
Fractional Recrystallization Behavior of Impurity-Doped Commercially Pure Aluminum
}

\author{
Mohammad Salim Kaiser \\ Directorate of Advisory, Extension and Research Services \\ Bangladesh University of Engineering and Technology, Dhaka-1000, Bangladesh \\ Phone: +880-2-9663129; Fax: +880-2-9665622 \\ e-mail: mskaiser@iat.buet.ac.bd
}

\begin{abstract}
This manuscript reports the effects of trace impurities on the fractional recrystallization behavior of commercially pure aluminum. To allow the recrystallization cold rolled by $75 \%$ alloy samples are annealed isothermally at $700^{\circ} \mathrm{K}$ for different time up to 60 minutes. Recrystallization kinetics is evaluated from the microhardness variation of the different annealed samples. The JMAK type analysis is also used to study the recrystallization behavior as well as to observe the correlation with the experimental results. The behavior of the fraction recrystallization between two methods the trace impurities added alloys is evidence for the higher variation as to form GP zones and metastable phases during annealing. Higher addition shows the more variation as the formation of higher fraction phases. The microstructural study reveals that annealing at $700^{\circ} \mathrm{K}$ for 30 minutes the alloys attain almost fully recrystallized state.
\end{abstract}

Keywords: Al alloys, impurities, annealing, precipitate, recrystallization

\section{INTRODUCTION}

Pure aluminum does not provide high strength [1]. However, the mechanical properties of aluminum can be enhanced by adding alloying elements to particular applications [2-4]. Though unintended effects on other properties may happen in case of improving one particular property through addition of alloying substance. Basically, microstructure can influence the mechanical properties of a metal [5-7]. A uniform, fine final microstructure is chosen for low-temperature as well as high-strength applications. Recrystallization generally causes reduction in the strength and hardness of a material but shows a simultaneous increase in the ductility [8,9]. Recrystallization defines a process where a new set of defects-free grain replaces the deformed grains. Then it nucleates and grows until the original strength and hardness of a material and a simultaneous increase in the ductility grains have been entirely consumed. It usually occurs with a reduction in the strength and hardness of a material as well as a simultaneous increase in the ductility [10-12]. Thus, the process is a deliberate step in metals processing or may appear as an undesirable byproduct of another processing step. The frequent industrial uses are softening of metals which were previously hardened or rendered brittle by cold work and control of the grain structure in the final product [13]. For structural applications which require high strength, low volume fraction of recrystallization is necessary [14]. Recrystallization can vary throughout the structure of hot-rolled thick aluminum plates and the possible reasons are - due to variation in solute and dispersoid concentration, particle size and distribution, deformation conditions, quench rates, and temperature [15, 16]. Here, some impurities in aluminum may exert from the melt environment as the refractory linings of furnaces, ladles, reactors or launders etc. during the time of casting. The remained impurities from the environment, which are difficult to entirely remove from the recycled metals [17]. The recovery and 
recrystallization of commercially pure aluminum is dependent on the content of impurities and whether or not the impurities are dissolved in the matrix $[18,19]$.

According to numerous papers it is established that recrystallization behavior are prime factors for controlling the properties of a material and it depends on the elements present into the materials. In this article, the methods of micro hardness variation is applied to study the recrystallization kinetics in directly cold rolled commercially pure aluminum containing trace impurities. It is well known that the isothermal kinetics of the recrystallization process followed the Johnson-Mehl-Avrami-Kolmogorov (JMAK) relationship of the particular material system [20]. The recrystallization kinetics is also analyzed as well as compared with the experimental result where JMAK type behavior is assumed and obtained from micro-hardness variation for these alloys.

\section{EXPERIMENTAL METHODS}

Commercially pure aluminum ingot with a purity of $99.80 \%$ was taken as the starting material for the process of melting. First the commercially pure aluminum say Alloy 1 was melted in a gas fired clay-graphite crucible under suitable flux cover (degasser, borax etc) idiom as Alloy 2 and then it was re-melted again to arrange Alloy 3 . The temperature of the melt was always kept at $1050 \pm 150 \mathrm{~K}$ using an electronic controller. The melt was allowed to be evenly distributed under stirring about at $1000^{\circ} \mathrm{K}$ and poured in a steel mould preheated to $525^{\circ} \mathrm{K}$. Size of the mould was $17.0 \times 51.0 \times 200.0$ in millimeter. Homogenizing heat treatment was carried out at a temperature of $725^{\circ} \mathrm{K}$ for 12 hours to redistribute the precipitating elements more consistently throughout the alloys. Then the alloys was solution heat-treated at $800^{\circ} \mathrm{K}$ for two hours and water quenched subsequently to obtain a super saturated single phase region. The chemical compositions of the experimental alloys were analyzed by Foundry-Master compact Optical Emission Spectroscopy, made in Germany and the results are listed in Table 1. Cold rolling of the cast alloys at $75 \%$ reduction was carried out with a laboratory scale $10 \mathrm{HP}$ capacity rolling mill. The sample sizes were $16 \times 16 \times 50 \mathrm{~mm}$ and in every passes about $1.0 \mathrm{~mm}$ of deformation was given. As a result thickness of the samples became $4.0 \mathrm{~mm}$ as of the 16 $\mathrm{mm}$ thick. Cold rolled samples were annealed isothermally at $700^{\circ} \mathrm{K}$ for time ranging from 30 second to 60 minutes. Hardness of different alloys at different annealed condition was measured using a Digital Micro Vickers Hardness Tester HVS-1000Z, China. Where a load of $1 \mathrm{Kg}$ and dwell time of 10 seconds were used for assessing the softening behavior of the alloys. An Indian made Electric Conductivity Meter, type 979 was used for measuring the electrical conductivity of the alloys after different possessed conditions. 15 $\mathrm{mm} \times 15 \mathrm{~mm}$ finished surface were prepared for these measurements created by grinding as well as polishing. Next the conductivity data was converted into electrical resistivity for plotting the graph. An optical microscopy observation was also made on the cold rolled and annealed samples to determine the microstructure and the granular texture of the studied materials. SKU: OMM300-T Inverted Metallurgical Compound Microscope, USA was used for this purpose. In order to view the microstructure, the samples were polished finally with alumina and the etchant used was Keller's reagent.

Table 1. Chemical Composition by wt \%t of the experimental alloys as measured by GD-OES

\begin{tabular}{|c|c|c|c|c|c|c|c|c|c|c|c|}
\hline Alloy & Si & $\mathrm{Fe}$ & $\mathrm{Zn}$ & $\mathrm{Cr}$ & $\mathrm{Cu}$ & $\mathrm{Mg}$ & Mn & $\mathrm{Ni}$ & $\mathrm{Pb}$ & Sn & Al \\
\hline 1 & 0.0210 & 0.1806 & 0.0004 & 0.0016 & 0.0022 & 0.0016 & 0.0021 & 0.0000 & 0.0000 & 0.0000 & $\mathrm{Bal}$ \\
\hline 2 & 0.4647 & 0.5820 & 0.0553 & 0.0294 & 0.0091 & 0.0071 & 0.0041 & 0.0175 & 0.0065 & 0.0017 & $7 \mathrm{Bal}$ \\
\hline 3 & 0.8357 & 0.6273 & 0.0526 & 0.0453 & 0.0150 & 0.0061 & 0.0185 & 0.0195 & 0.0085 & 0.0019 & $9 \mathrm{Bal}$ \\
\hline
\end{tabular}

\section{RESULTS AND Discussion}

\subsection{Isothermal Annealing}

When isothermally annealed at $700^{\circ} \mathrm{K}$, the variation of microhardness of the experimental alloys as a function of annealing time is presented in Fig.1. It is seen from the graph that the nature of initial softening is similar for all three alloys. Alloy 1 commercially pure aluminum demonstrates an extremely quick and sharp decrease in hardness followed by a constant value. Some variations are observed in trace impurity 
added Alloy 2 and Alloy 3 . The initial softening of the cold worked alloys during annealing is due to rearrangement of dislocations [21, 22]. Prickly decreases in hardness are shown for all the alloys while they are annealed at more time. It is because in higher temperature the precipitates tend to become coarser and coarse precipitates are not as effective as fine precipitates to inhibit the dislocation movement. Coarse precipitates do not proffer enough resistance as recrystallization takes place easily [23, 24]. In case of trace added alloys a small variation are observed in recystalization behavior because of a very small amount of dissolved iron and silicon delays the recovery and recrystallization.

The variation of resistivity of the experimental alloys when isothermally annealed at different time is provided in Fig. 2. The small drop in resistivity occurs at the initial stage due to stress relieving through dislocation rearrangement of cold rolled alloys [25, 26]. The foremost drop in resistivity is due to dissolve of GP zones followed the subsequent increase in resistivity is due to the appearance of formation of fine precipitates metastable phases [27, 28]. Recovery and dissolution of metastable phases already present into the matrix are also responsible for the steep drop in resistivity of the alloys. At higher annealing times the ending decline in resistivity is associated with particle coarsening as well as the recrystallization behavior of the alloys [29].

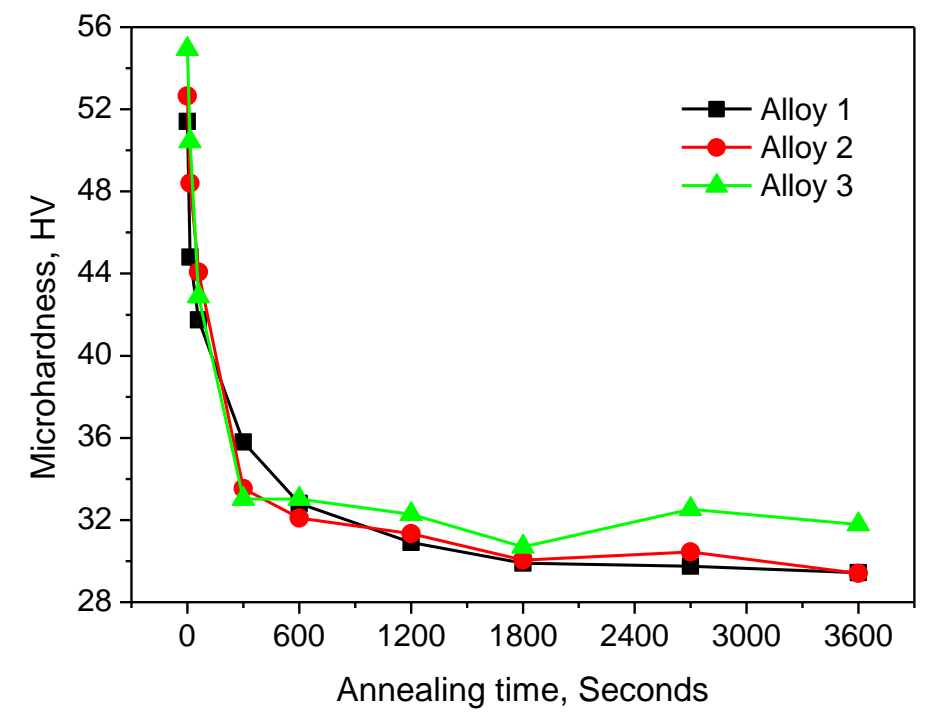

Figure 1. Variation of microhardness, Isothermal annealed at $700^{\circ} \mathrm{K}$

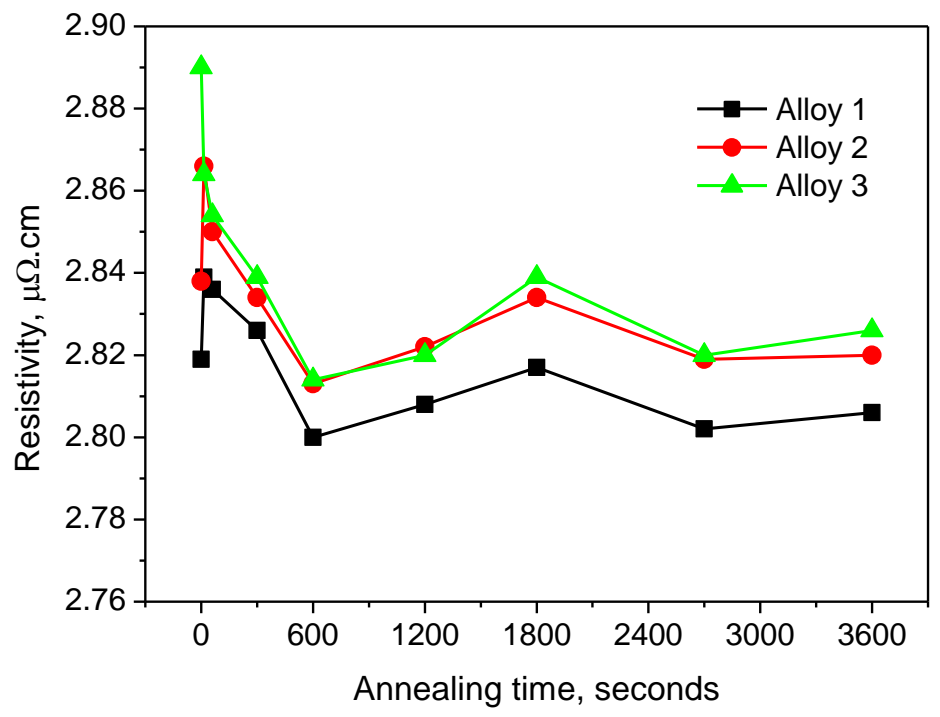

Figure 2. Variation of resistivity, Isothermal annealed at $700^{\circ} \mathrm{K}$ 


\subsection{Recrystallization kinetics from microhardness variation}

The maximum and minimum microhardness values of the experimental alloys were used to determine the kinetics of recrystallization. The maximum microhardness values achieved from cold rolled alloys and minimum was from completely recrystallized samples respectively. The obtained microhardness values of the three alloys are listed in Table 2.

Through the following formula these microhardness values was used to obtain the recrystallized fraction of the experimental alloys [30]: -

$$
X=\frac{H_{\max }-H_{i}}{H_{\max }-H_{\min }}
$$

Where $H_{\text {max }}$ is maximum hardness corresponding to deformed sample $(\mathrm{t}=0), H_{\min }$ is minimum hardness corresponding to fully recrystallized sample and $H_{i}$ is microhardness after a given annealing time [31].

When the alloys annealed isothermally at $773^{\circ} \mathrm{K}$ for one hour fully recrystallied sample got hold. Fig 3 illustrates the variation of fraction recrystallized obtained from microhardness values of the alloys annealed at $700^{\circ} \mathrm{K}$ for different time. The commercially pure aluminium Alloy 1 shows the maximum values of fraction recrystallized followed by trace impurity added Alloy 2 and Alloy 3 . It is due to formation of higher fraction of GP zones and metastable phases during annealing as they content higher impurities. Dissolved iron and silicon also hinder the recrystallization process of the trace added alloys.

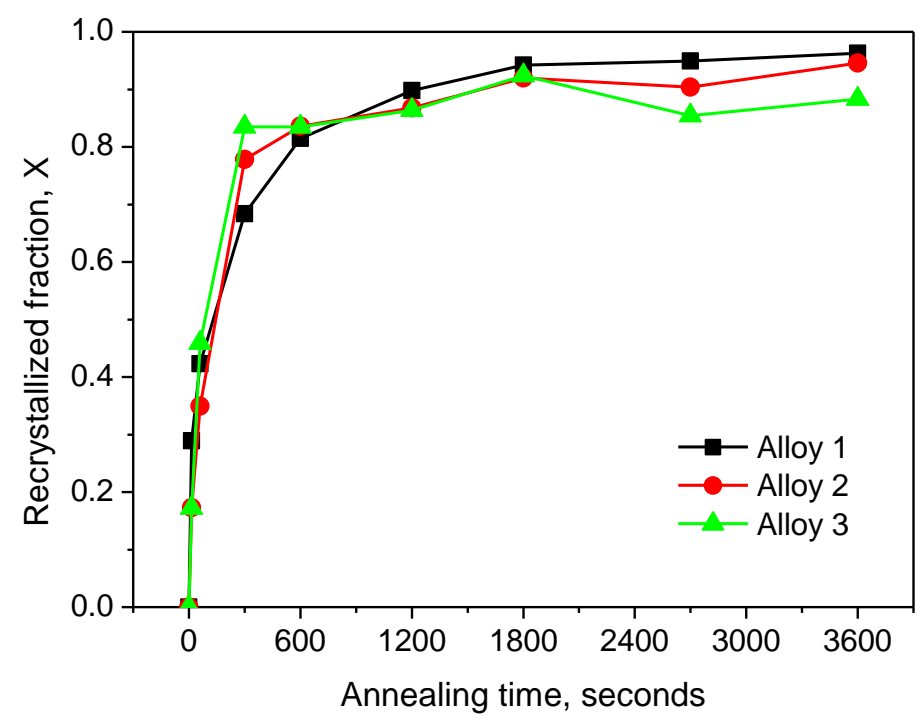

Figure 3. Variation of recrystallization kinetics with annealing time obtained from experimental data of microhardness

The Johnson-Mehl-Avrami-Kolmogorov (JMAK) theory can be applied in a mathematical form to the investigation of the recrystallization kinetics of the experimental alloys [29, 32]. To study the variation of fraction recrystallized with annealing time the JMAK relationship is expressed as follows:

$$
X=1-\exp \left[-(k t)^{n}\right]
$$

Here $X$ is the recrystallized fraction, $k$ is the temperature dependent constant, $t$ is time and $n$ is the JMAK exponent. 
Using a logarithmic expression this equation can be simplify to a linear relationship as follows.

$$
\ln \left[\ln \left(\frac{1}{1-X}\right)\right]=n \ln (t)+n \ln (k)
$$

Exponent $\mathrm{n}$ and the parameter $\mathrm{k}$ can be obtained from the coordinate as the linear relationship with a slope equal to the JMAK exponent displayed in Fig. 4.

The values of the JMAK exponent $n$ and parameter $k$ can be used to obtain recrystallization kinetics of the alloys annealed at $700^{\circ} \mathrm{K}$. The comparison of recrystallization kinetics for experimental alloys obtained from micro-hardness data and JMAK type analysis are shown in Fig. 5-7. Commercially pure aluminum Alloy 1, impurities added Alloy 2 and Alloy 3 contents different level of impurities as a result they display the different slope for their recrystallization behavior.

$$
\begin{aligned}
& X=1-\exp \left[-(0.005040 \times t)^{0.43350}\right] \text { for Alloy } 1 \\
& X=1-\exp \left[-(0.003443 \times t)^{0.49188}\right] \text { for Alloy } 2 \\
& X=1-\exp \left[-(0.003752 \times t)^{0.42470}\right] \text { for Alloy } 3
\end{aligned}
$$

Table 2. Experimental value of maximum, minimum hardness and JMAK exponent of the alloys

\begin{tabular}{ccccc}
\hline Alloy & $H_{\max }$ & $H_{\min }$ & $\mathbf{n}$ & $\mathbf{k}$ \\
\hline 1 & 51.40 & 28.58 & 0.43350 & 0.005040 \\
2 & 52.65 & 28.08 & 0.49188 & 0.003443 \\
3 & 54.93 & 28.70 & 0.42470 & 0.003752 \\
\hline
\end{tabular}

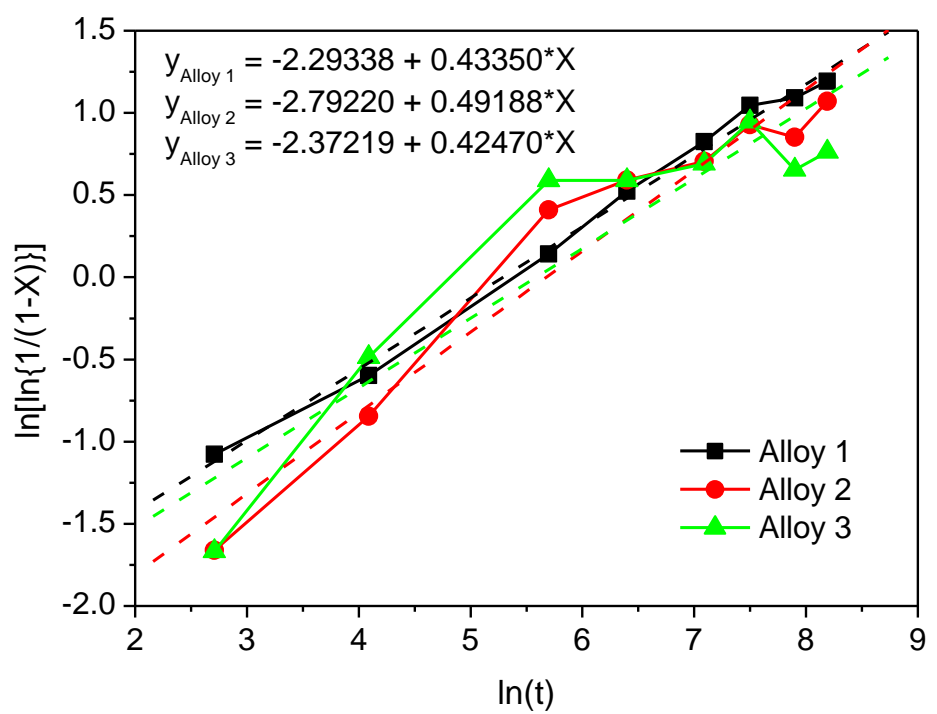

Figure 4. Plot of $\ln [\ln \{1 /(1-X)\}] V s . \ln (t)$, showing a linear relationship with a slope equal to the JMAK exponent 
Alloy 1 the commercially pure aluminum shows the minimum variation between the two methods of recrystallization fraction (Fig. 5). The alloy contents the least impurities which forms insignificant amount of intermetallics, so the effectiveness is small. Trace impurities added Alloy 2 and Alloy 3 behave the higher dissimilarity as shown in Fig. 6 and Fig. 7 respectively. These trace added alloys form higher fraction of GP zones and metastable phases during annealing causes the higher variation. Alloy 3 shows the highest variation of recrystallization fraction between two methods due to highest level of impurities in attendance into the alloy. Trace impurities form small amount of different precipitates which also inhibit the recrystallization process of the impurity-doped commercially pure aluminum alloys.

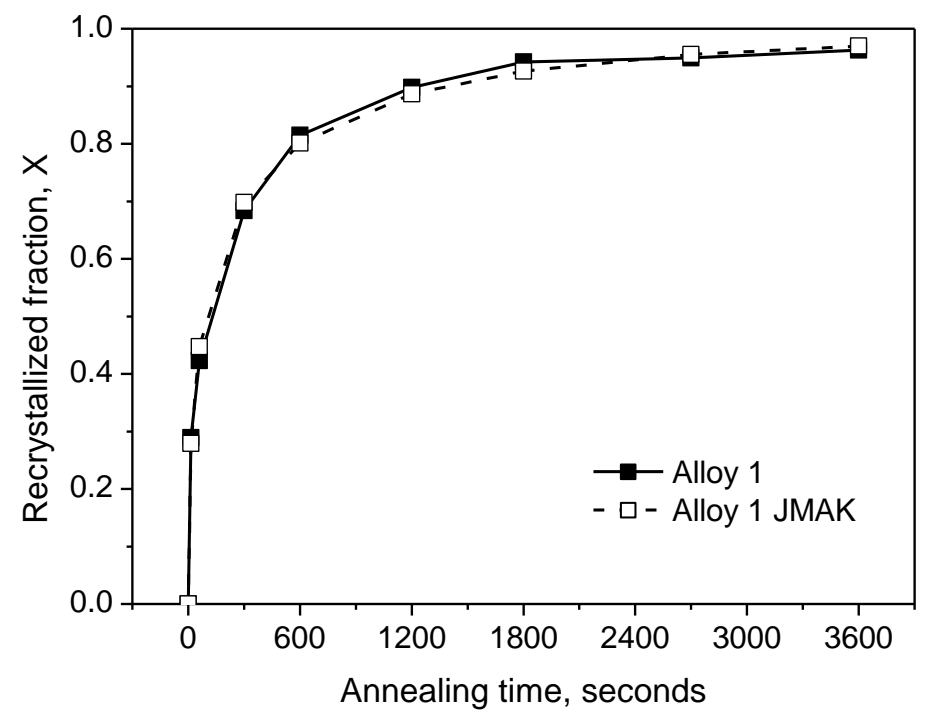

Figure 5. Comparison of recrystallization kinetics for commercially pure aluminum Alloy 1 obtained from Micro-hardness data and JMAK type analysis

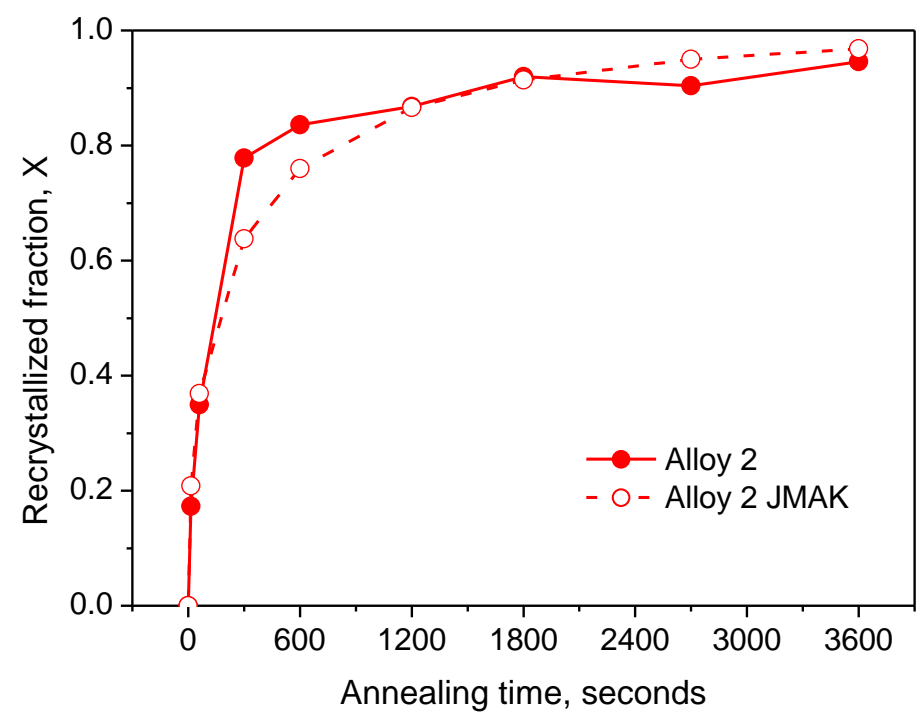

Figure 6. Comparison of recrystallization kinetics for impurities added Alloy 2 obtained from Microhardness data and JMAK type analysis 


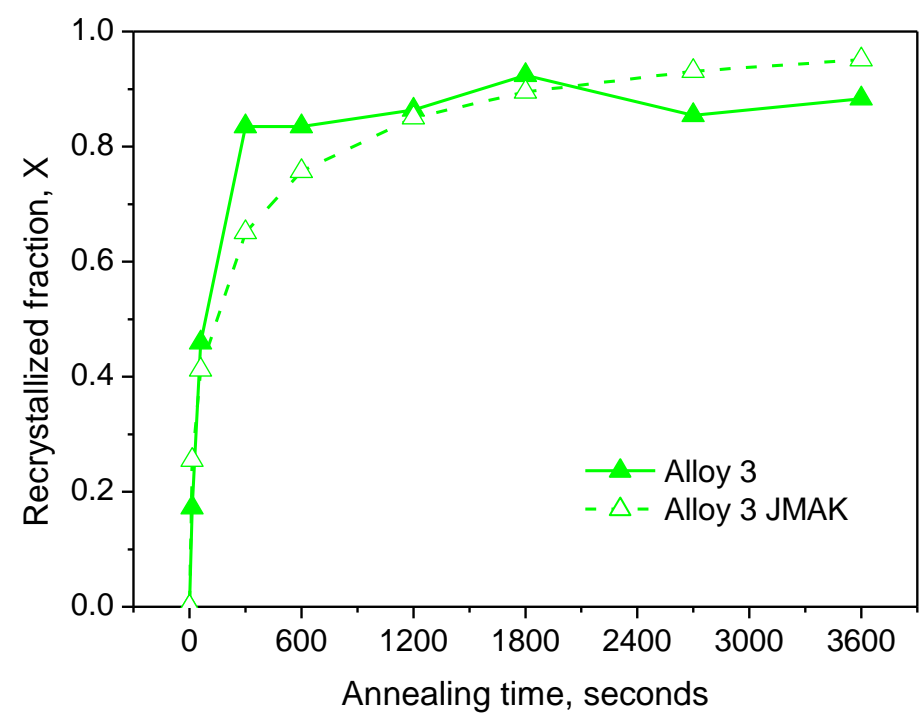

Figure 7. Comparison of recrystallization kinetics for impurities added Alloy 3 obtained from Microhardness data and JMAK type analysis

\subsection{Optical micrographs}

The optical microstructures of solution treated followed by $75 \%$ cold rolled commercially pure aluminum Alloy 1, impurities added Alloy 2 and Alloy 3 are shown in Fig. 8a-c. All the microstructure consists of heterogeneous grains with dispersed in rolling directions. Alloy 1 contents the least amount of impurities like $\mathrm{Fe}$, Si etc., so during solution treatment the intermetallics precipitated are small in both amount and size. The precipitates gradually increased with the addition of the impurities into the alloys. They become very fine when the alloy is solution treated of near-rapid cooling. To compare, Fig. 8c also shows the fine intermetallics in Alloy 3. It is also observed that the intermetallics are extremely refined by the fast cooling in the high $\mathrm{Fe}$ and $\mathrm{Si}$ containing alloys (Alloy 2 and Alloy 3) [33].

After annealing treatment at $700^{\circ} \mathrm{K}$ for 30 minutes, most residual phases are dissolved into $\alpha$-Al matrix, and the grain boundaries become thinner and clear (Fig. 9a-c). The grain shapes are equiaxed. There are different trace impurities elements present in to the alloys which may form intermetallic particles during casting and annealing but at higher annealing temperature and time most of these precipitates are distributed along with grain boundaries. The dissolution temperature of phases containing $\mathrm{Fe}$ and $\mathrm{Si}$ elements is very high. So small indissoluble these phases can still be present within the grains and beside the grain boundaries [34, 35].
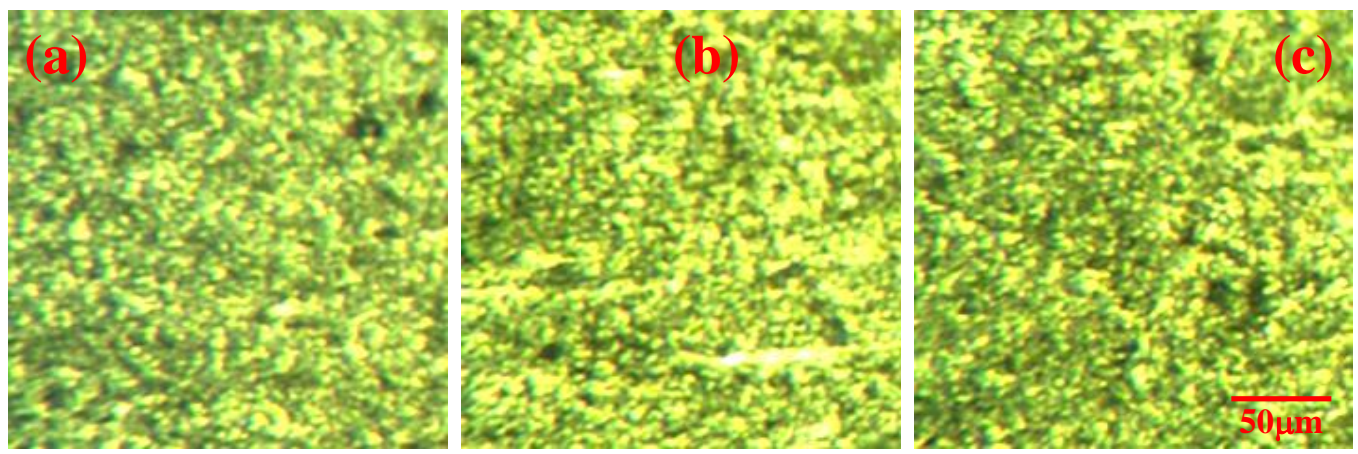

Figure 8. Optical micrographs showing microstructure of $75 \%$ cold rolled (a) commercially pure aluminum Alloy 1, (b) impurities added Alloy 2 and (c) Alloy 3 


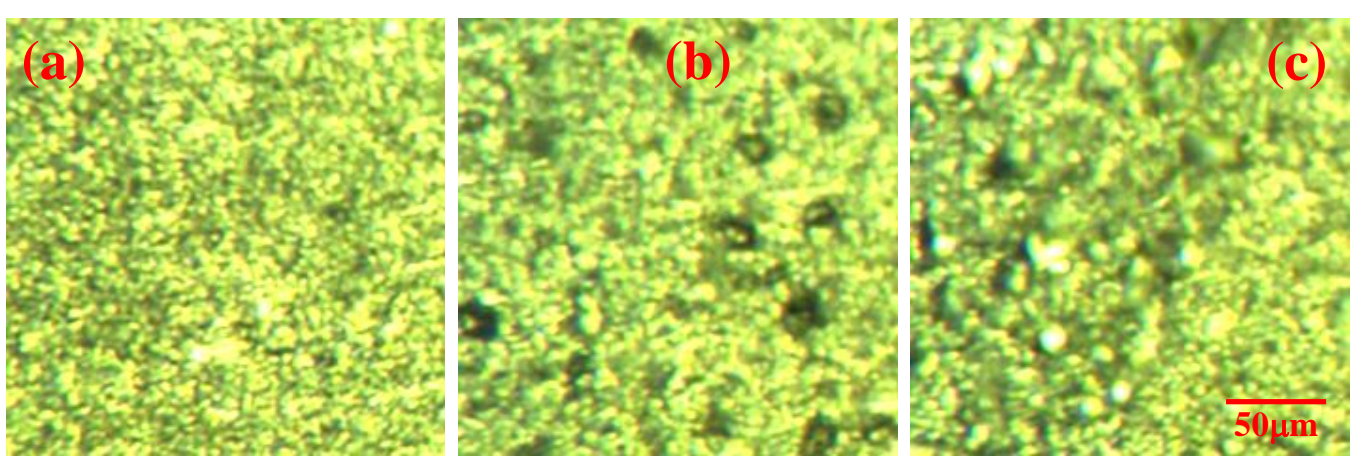

Figure 9. Optical micrographs of $75 \%$ cold rolled subjected to annealing heat treatments at $700^{\circ} \mathrm{K}$ for 30 minutes (a) commercially pure aluminum Alloy 1, (b) impurities added Alloy 2 and (c) Alloy 3

\section{CONCLUSION}

This research has investigated the kinetics of recrystallization for impurities added commercially pure aluminum that is obtained from Micro-hardness data and JMAK analysis. From this work, the principal conclusions can be drawn as follows:

Commercially pure aluminum shows the little difference between two methods. Higher impurities added alloys show the larger different due to formation of higher fraction of GP zones and metastable phases during annealing. Small amount of dissolved iron and silicon also delays the recovery and recrystallization. All the alloys reached fully recrystallized state after 1800 seconds, while trace impurities added alloys are slightly later when isothermally annealed at $700^{\circ} \mathrm{K}$.

\section{ACKNOWLEDGEMENTS}

The author acknowledges all kind of support given by the DAERS office of Bangladesh University of Engineering and Technology, Dhaka-1000.

\section{REFERENCES}

1. Polmear, I., Stjohn, D., Nie, J.F., and Qian, M., "Light Alloys: Metallurgy of the Light Metals", 5 $5^{\text {th }}$ Edition, Butterworth-Heinemann, UK, 2017.

2. Guel, I.E., Gallardo, C.C., Ruiza D.C.M., and Yoshidaa, M.M., "Graphite nanoparticle dispersion in 7075 aluminum alloy by means of mechanical alloying", Journal of Alloys and Compounds. Vol. 483, No. (1-2), (2009), pp. 173-177.

3. Kaiser, M.S., Sabbir, S. H., Kabir, M.S., Rahman, M., and Nur, M.A., "Study of mechanical and wear behaviour of hyper-eutectic Al-Si automotive alloy through $\mathrm{Fe}$, $\mathrm{Ni}$ and $\mathrm{Cr}$ addition”, Journal of Materials Research, Vol. 21, No. 4, (2018), pp. 1-9.

4. Kaiser, M.S., and Banerjee, M.K., "Effect of ternary scandium and quaternary zirconium and titanium additions on the tensile and precipitation properties of binary cast Al-6Mg alloys", Jordan Journal of Mechanical and Industrial Engineering, Vol. 2, No. 2, (2008), pp. 93-99.

5. Zhen, L., Hu, H., Wang, X., Zhang, B., and Shao, W., "Distribution characterization of boundary misorientation angle of 7050 aluminum alloy after high-temperature compression", Journal of Materials Processing Technology, Vol. 209, (2009), pp. 754761.

6. Field, D.P., Behrens, L., and Root, J.M., "Identification of particle stimulated nucleation during recrystallization of AA 7050", Computers, Materials, and Continua, Vol. 1, No. 3, (2009), pp. 171-183.

7. Hu, H.E., Zhen, L., Zhang, B.Y., Yang, L., and Chen, J.Z., "Microstructure characterization of 7050 aluminum alloy during dynamic recrystallization and dynamic recovery", Materials Characterization, Vol. 59, (2008), pp. 1185-1189.

8. Robson, J.D., "Microstructural evolution in aluminum alloy 7050 during processing", Materials Science and Engineering A, Vol. 382, (2004), pp. 112-121. 
9. Deng, Y.L., Wan, L., Zhang, Y., and Zhang, X.M., "Evolution of microstructures and textures of $7050 \mathrm{Al}$ alloy hot-rolled plate during staged solution heat-treatments", Journal of Alloys and Compounds, Vol. 488, (2010), pp. 88-94.

10. Schouwenaars, R., Duran, H.A., Jacobo, V.H., and Ortiz, A., "Microstructure, texture and recrystallisation mechanisms of an Al-20\%Sn deformation processed metalmetal composite", Materials Science Forum, Vol. 715-716, (2012), pp. 522-527.

11. Vandermeer, R.A., and Jensen, D.J., "Quantification of microstructural evaluation and texture development during recrystallization", Textures and Microstructures, Vol. 26-27, (1996), pp. 263-279.

12. Wu, G., and Jensen, D.J., "Automatic determination of recrystallization parameters based on EBSD mapping, Materials Characterization", Vol. 59, (2008), pp. 794-800.

13. Engler, O., and Hirsch, J., "Texture control by thermomechanical processing of AA6xxx Al-Mg-Si sheet alloys for automotive applications - a review", Materials Science and Engineering A, Vol. 336, No. 1-2, (2002), pp. 250-262.

14. Alaneme, K.K., and Okotete, E.A., "Recrystallization mechanisms and microstructure development in emerging metallic materials: A review", Journal of Science: Advanced Materials and Devices, Vol. 4, No. 1, (2019), pp. 19-33.

15. Jia, Z., Hu, G., Forbord, B., and Solberg, J.K., "Effect of homogenization and alloying elements on recrystallization resistance of Al-Zr-Mn alloys", Materials Science and Engineering A, Vol. 444, (2007), pp. 284-290.

16. Robson, J.D., and Pragnell, P.B., "Modelling $\mathrm{Al}_{3} \mathrm{Zr}$ dispersoid precipitation in multicomponent aluminium alloys", Materials Science and Engineering A, Vol. 352, (2003), pp. 240-250.

17. Capuzzi, S., and Timelli, G., "Preparation and melting of scrap in aluminum recycling: A Review", Metals, Vol. 8, No. 4, (2018), pp. 1-24.

18. Kaiser, M.S., "Trace Impurity effect on the precipitation behaviuor of commercially pure aluminium through repeated melting", European Journal of Materials Science and Engineering. Vol. 5, No. 1, (2020), pp. 37-48.

19. Yoshida, H. and Ookubo, Y., "Effect of precipitation of impurities during annealing on the rate of recovery and recrystallization in 1050 aluminum hot-rolled sheets", Materials Transactions, Vol. 56, No. 12, (2015), pp. 1960-1967.

20. Kooi, B.J., "Extension of the Johnson-Mehl-Avrami-Kolmogorov theory incorporating anisotropic growth studied by Monte Carlo simulations", Physical review. B, Vol. 73, No. 5, (2006), pp. 1-13.

21. Kaiser, M.S., Shorowordi, K.M. and Rashed, H.M.M.A., "Effect of rolling on the fractional recrystallization behavior of $\mathrm{Al}-\mathrm{Mg}$ and $\mathrm{Al}-\mathrm{Mg}-\mathrm{Zr}$ alloys", Journal of Mechanical Engineering, Bangladesh, Vol. 48, No. 1, (2018), pp. 24-29.

22. Humphreys, F.J, and Hatherly, M., "Recrystallization and related annealing phenomena", $2^{\text {nd }}$ Edition, Oxford, UK, 2004

23. Adeosun, S.O., and Balogun, S.A., "Effect of recrystallization temperature and time on the AA1060 aluminum alloy", The Journal of The Minerals, Metals and Materials Society, Vol. 63, No.5, (2011), pp. 50-54.

24. Tajally, M., and Huda, Z., "Recrystallization kinetics for aluminum alloy 7075 , Metal Science and Heat Treatment", Vol. 53, No.5-6, (2011), pp. 213-217.

25. Volkov, A.Y., "Improvements to the microstructure and physical properties of Pd-CuAg alloys", Platinum Metals Review, Vol. 48, No. 1, (2004), pp. 3-12.

26. Kaiser, M.S., "Effect of scandium on the softening behaviour of different degree of cold rolled Al-6Mg alloy annealed at different temperature", International Journal of Advances in Materials Science and Engineering, Vol. 1, No. 1, (2014), pp. 39-49.

27. Liu, Z.X., Zhang, X.M. and Tang, J., "The influences of precipitates on resistivity of 6101 aluminium alloy in aging, Journal of Functional Materials", Vol. 45, No. 2, (2014), pp. 2119-2128.

28. Osuch, P., Walkowicz, M., Knych,T., and Dymek, S., "Impact of the direct ageing procedure on the age hardening response of Al-Mg-Si 6101 alloy", Materials, Vol. 11, No. 7, (2018), pp. 1-13.

29. Kaiser, M.S., "Fractional recrystallization kinetics in directly cold rolled Al-Mg, Al-MgSc and Al-Mg-Sc-Zr alloy", Iranian Journal of Materials Sciences and Engineering, Vol. 11, No. 4, (2014), pp. 80-87. 
30. Kaiser, M.S., and Dutta, S., "Recrystallization kinetics in aluminum piston, Procedia Engineering", Vol. 90, (2014), pp. 188-192.

31. Chen, S.P., Hanlon, D.N., Zwaag, V.S., Pei, Y.T., and Hosson, J.T., "Quantification of the recrystallization behavior in Al-alloy AA1050", Journal of Materials Science, Vol. 37, (2002), pp. 989-995.

32. Robson, J.D., Pragnell, P.B., "Modelling $\mathrm{Al}_{3} \mathrm{Zr}$ dispersoid precipitation in multicomponent aluminium alloys", Materials Science and Engineering, Vol. A352, (2003), pp. 240-250.

33. Dong, J., Dong, Q., Dai, Y., Xing, H., Han, Y., Ma, J., Zhang, J., Wang, J., and Sun, B., "Microstructure evolution in high purity aluminum single crystal processed by equal channel angular pressing (ECAP)", Materials, Vol. 10, No. 87, (2017), pp. 1-8.

34. Zhang, L., Wang, Y., Yang, X., Li, K., Ni, S., Du, Y., and Song, M., "Texture, microstructure and mechanical properties of 6111 aluminum alloy subject to rolling deformation", Materials Research, Vol. 20, No. 5, (2017), pp. 1360-1368.

35. Radovic, L., and Nikacevic, M., "Microstructure and properties of cold rolled and annealed Al-Mg alloys", Scientific Technical Review, Vol. 8, No. 2, (2008), pp. 14-20. 